\title{
Prevalence and etiology of dental trauma in schoolchildren aged 6 to 12 years
}

Ana de Lourdes Sá de Lira', Luís Paulo da Silva Dias ${ }^{1}$, Cassius Wander Coelho Martins ${ }^{1}$, Tito Cacau Sousa Santos ${ }^{1}$

1 Piauí State University - UESPI, School of Dentistry, Department of Clinical Dentistry, Area of Integrated Clinic, Parnaíba, PI, Brazil
Corresponding author: Ana de Lourdes Sá de Lira Universidade Estadual do Piauí,

Faculdade de Odontologia Rua Senador Joaquim Pires 2076 Ininga. Fone (86) 999595004

CEP: $64049-590$

Teresina-PI-Brasil

email: anadelourdessl@hotmail.com

Received: November 12, 2017

Accepted: June 24, 2018
Aim: To investigate the prevalence and etiological factors of dental trauma in school-age children aged 6 to 12 years. Methods: A study was developed in children and adolescents between the ages of 6 and 12 of both genders enrolled in 3 municipal public schools. An oral examination of the permanent or deciduous incisors was performed, if they were still present in the oral cavity, to evaluate the presence of dental trauma, need for treatment and sequels, and the method of examination and classification of dental trauma of O'Brien. Results: The prevalence of dental trauma was $4.03 \%(n=29)$. The most verified traumas were enamel crack / enamel fracture and enamel / dentin fracture without pulp exposure. It was observed that the most affected teeth were the permanent upper central incisors and the age at which trauma was most observed was 11 years, the main etiological factor was fall from a height, in $65.3 \%$ of schoolchildren $(n=19)$. Conclusion: The prevalence of dental trauma was $4.03 \%$, with no statistically significant difference between genders. The permanent right upper central incisor was the most affected, occurring predominantly at home and at school. The dissemination of information about dental trauma and emergency protocols to parents and teachers need to be encouraged.

Keywords: Tooth Injuries. Dentition, mixed. Pediatric Dentistry. 


\section{Introduction}

Traumatic dental injury (TDI) is a common oral disorder in school-age children. It is caused by an external impact on the tooth and surrounding tissues, it constitutes a public health problem in our society, in increasing proportions of the population being affected, with attendant aesthetic, psychological, social and therapeutic damages, besides the high costs of oral rehabilitation, when accidents with dental losses occur ${ }^{1,2}$.

Due to the evident decay of caries in Brazil and the low prevalence of periodontal disease in younger populations, traumatic lesions are documented as one of the most serious problems associated with oral health, becoming a public health problem among children and adolescents. Its prevalence rate is high, and immediate care is necessary for a good prognosis ${ }^{3,4}$.

Although guidelines of the International Association of Dental Traumatology (IADT) recommend focusing on the treatment of acute dental injuries, other sequelae of trauma such as crown discoloration should be considered ${ }^{1}$. The treatment for dental trauma varies with each patient, degree of severity, or duration of trauma ${ }^{5}$.

The high rates of auto accidents, extreme sports, urban violence with firearms, falls and wrestling have favored the occurrence of this type of trauma in dental emergencies. In the vast majority of accidents children and adolescents are involved ${ }^{5,6}$. Recent studies have shown an association between illicit drug use and TDI, considering this association as a worrying risk factor for fracture or tooth loss ${ }^{7}$. The upper central incisors are the teeth most prone to trauma, the most common fractures being those involving only enamel or enamel and dentin without pulp exposure ${ }^{8}$. Obtaining epidemiological data from TDI is extremely important for the planning, execution and evaluation of actions in oral health, since variations in prevalence evidenced the need for successive studies and identification of factors associated with it ${ }^{9,10}$.

It was desired to perform this research in schoolchildren, between 6 and 12 years of age, for the following reasons; because it is the period of mixed dentition, children at this age practice various sports activities and are very rxplorative, the permanent teeth I some may still be undergoing their eruptive process thus making management a bit more complicated, their chances of being exposed to dental traumas may be a bit increased as the tend to express some degree of malocclusion at this stage, since the permanent dentition has not yet been fully established.

The objective of this research was to investigate the prevalence and etiological factors of dental trauma in children of school age from 6 to 12 years.

\section{Materials and Methods}

A cross-sectional study was developed and the reference population consisted of children and adolescents between the ages of 6 and 12 of both genders enrolled in the municipal public schools network in the city of Parnaíba-Piaui. The descriptors used were dental trauma, mixed dentition, pediatric dentistry.

The researchers obtained a letter of Consent from the directors of the School Units São Francisco dos Capuchinhos School, Rev. Erasmo Martins Ferreira Presbyterian 
School and Caio Passos Municipal School, in the municipality of Parnaíba, Piauí. The research protocol was approved by the Research Ethics Committee of the State University of Piauí - CEP / UESPI, under opinion 1665.758.

According to the sample calculation 550 children should be examined, but this was exceeded during data collection to make the study more robust and all inclusive. The inclusion criteria were all children aged between 6 and 12 years, since it corresponded to the period of the mixed dentition, children whose parents or guardians gave consent and the children who accepted to participate in the research. As exclusion criteria, children under 6 years of age and over 12 years of age, due to permanent dentition, or the second erupting permanent molars and those with more than 12 years of age, due to permanent dentition, or the second erupting permanent molars, and those whose parents or guardians did not authorize the research.

Epidemiological questionnaire was applied to the participants and caregivers to make a survey about the circumstances that led to the event of the trauma. The children were examined by two researchers who were trained at the Clinical School of Dentistry (CEO) of the State University of Piauí to identify dental traumas. Subsequently, calibration exercises were performed with 20 children not participating in the sample plan, in a school in the municipality, according to the methodology described in another publication ${ }^{11}$. A pilot study was conducted involving 45 schoolchildren. As a result, its validity was observed, without adjustments. In order to measure intra and inter-examiner diagnostic reproducibiity, $10 \%$ of the total sample was double-checked by each of the examiners, with the Kappa coefficient for intra- and inter-examiner agreement being 0.99 and 0.98 , respectively.

The oral examination of the permanent or deciduous incisors was performed at the school, if they were still present in the oral cavity, to evaluate the presence of TDI and the need for treatment, being adopted the method of examination and classification of the dental trauma of O'Brien ${ }^{12}$, with the use of natural light and light of a LED flashlight for better visualization, gloves for procedures and wooden spatula.

For clinical examination, the teeth were dried with sterile gauze on all their surfaces ${ }^{13}$. When there was history and evidence of TDI, records were made in the odontogram.

The diagnostic criteria adopted to investigate the occurrence of TDI included, according to O'Brien ${ }^{12}$ : enamel crack and fracture, enamel / dentin fracture without and with pulp exposure, change in crown color, presence of aesthetic restorations, bonding of coronary fragment, total restoration of the crown of the permanent tooth, fistula or abscess and dental absence due to TDI.

A descriptive analysis of the data was carried out using frequency and number tables using Excel Windows 2013 software Microsoft $\circledast$. The possible association between the variables was verified by the Chi-square test and the non-parametric Mann-Whitney test. The significance level adopted was $5 \%$ and the statistical package SPSS for Windows 2010 (Social Package Statistical Science), version 20, was used for analysis.

\section{Results}

In this cross-sectional study, there were a total of 719 children, $65.5 \%$ were males $(n=378)$ and $34.5 \%$ females $(n=341)$, the prevalence of TDI in this study population was $4.03 \%$ 
$(n=29)$. From the chi-square statistical calculation, it was verified that there was no statistically significant difference in the association between the genders of the participants $X^{2}(1)=2.80, p=0.09$, considering the level of significance of random error of $5 \%$.

From the total prevalence of $4.03 \%$, the traumas were distributed according to the classification of Andersson et al. ${ }^{14}$, 2012: enamel crack / enamel fracture: $20.6 \%$ $(n=6)$; enamel / dentin fracture without pulp exposure: $65.5 \%(n=19)$; enamel / dentin fracture with pulp exposure: $3.4 \%(n=1)$; lateral dislocation $3.4 \%(n=1)$; intrusive dislocation 3.4\% $(n=1)$; avulsion: 3.4\% $(n=1)$, (Table 1)

Table 1. Frequency of distribution by gender $\mathrm{n}(\%)$ of the types of injuries observed (classification according to Andersson et $\mathrm{al}^{14}$, 2012).

\begin{tabular}{lccc}
\hline Dental trauma & Female $\mathbf{n}(\%)$ & Male $\mathbf{n}(\%)$ & Total $\mathbf{n}(\%)$ \\
\hline Enamel crack & $1(9.09)$ & $5(27.7)$ & $6(20.6)$ \\
\hline Enamel and dentin fracture/without pulp exposure & $7(63.6)$ & $12(66.6)$ & $19(65.5)$ \\
\hline Enamel and dentin fracture/with pulp exposure & $0(0.0)$ & $1(5.5)$ & $1(3.4)$ \\
\hline Lateral dislocation & $1(9.09)$ & $0(0.0)$ & $1(3.4)$ \\
\hline lintrusive dislocation & $0(0.0)$ & $1(5.5)$ & $1(3.4)$ \\
\hline Avulsion & $1(9.09)$ & $0(0.0)$ & $1(3.4)$ \\
\hline
\end{tabular}

Next, it was investigated if there was difference between the genders in the type of trauma of occurrence. For that, a non-parametric test was performed, Mann-Whitney. Which indicated that they did not differ statistically as to the level of occurrence of different types of trauma $[U=73.80(z=1.17) ; p=0.24]$.

The number and the traumatized teeth were shown in Figure 1. The most affected were the permanent upper central incisors ( $n=12$ cases), followed by the permanent upper right lateral incisor $(n=5)$ and by the primary teeth $51,52,62,81$ and 82 (one case for each tooth).

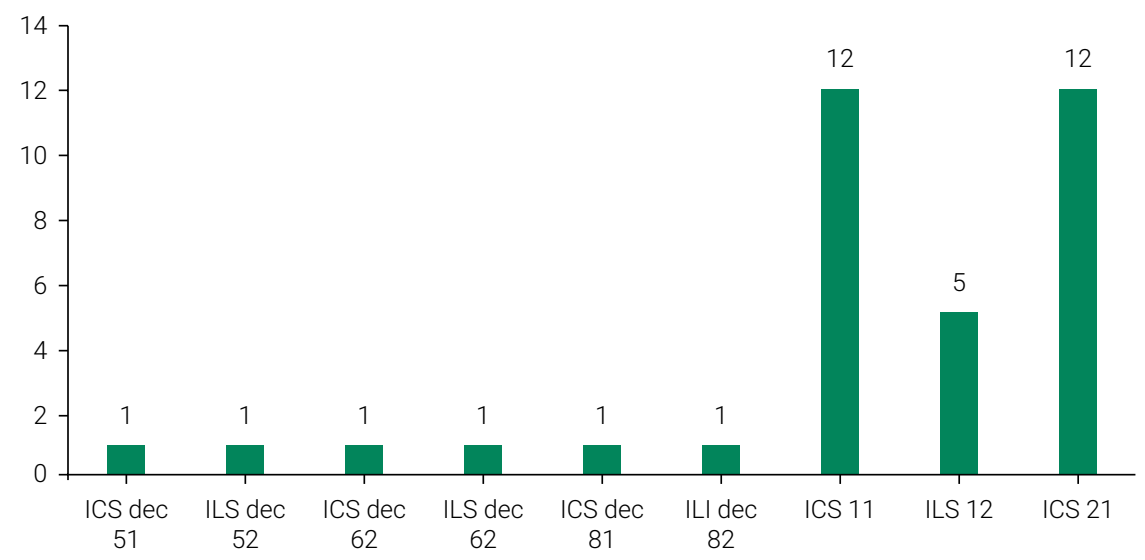

Figure 1. Distribution of affected teeth and their respective amounts. 
As to age, it was observed that the age at which most trauma occurred was 11 years with $20.68 \%(n=6)$. Followed by the age of $7,8,9$ and 10 years with $13.79 \%(n=4)$ respectively, 12 years with $10.34 \%(n=3)$ and finally the age of 6 years with $6.89 \%(n=2)$, Figure 2 .

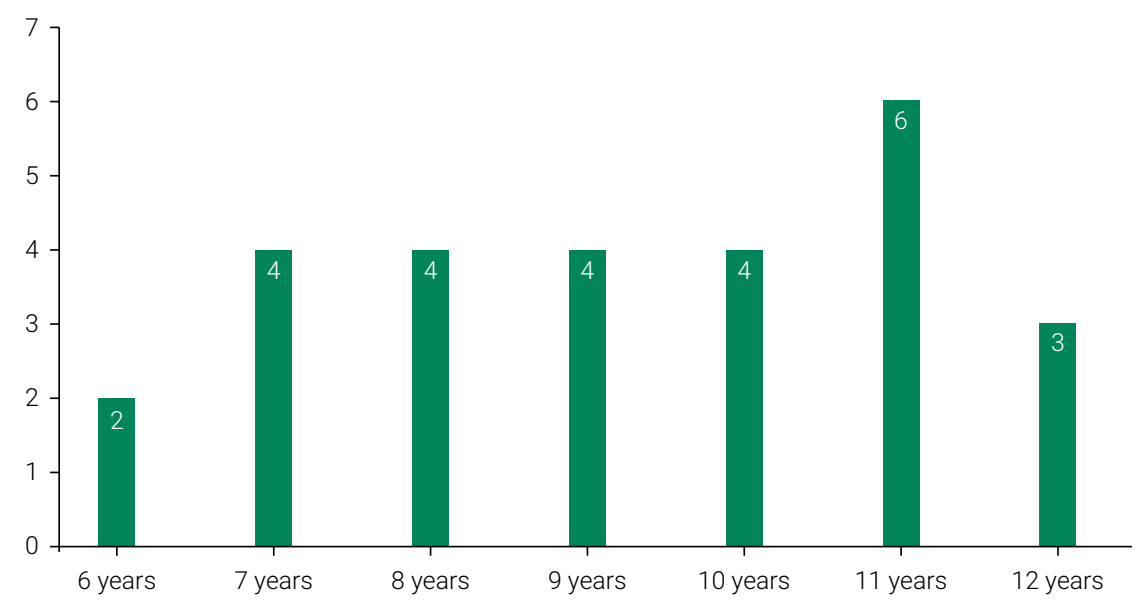

Figure 2. Number of schoolchildren affected by traumatic events by age.

According to the questionnaire given to the participants and parents/legal guardians, the main etiological factor was falling from a height, in $65.3 \%$ of the students $(n=19)$, followed by a collision with $10.2 \%(n=3)$, a bicycle crash with $10.2 \%(n=3)$, a sports accident $10.2 \%$ $(n=3)$. Another factor was an automobile accident with $3.4 \%(n=1)$ (Table 2).

The majority of schoolchildren who presented TD reported that the home and school were the places where the accident occurred, corresponding to $37.9 \%(n=11)$. Then, the most cited site was the street, involving $17.1 \%(n=5)$, and lastly, occurrences in leisure time were reported with $6.8 \%(n=2)$. (Table 2$)$.

Table 2. Distribution of schoolchildren according to etiology and place of dental injury

\begin{tabular}{lccccc}
\hline Etiology & Home $\mathbf{n}(\%)$ & School $\mathbf{n}(\%)$ & Recreation $\mathbf{n}(\%)$ & Street $\mathbf{n}(\%)$ & Total $\mathbf{n}(\%)$ \\
\hline Fall & $11(37.9)$ & $6(20.6)$ & $1(3.4)$ & $1(3.4)$ & $19(65.3)$ \\
\hline Collision with people /objects & $0(0.0)$ & $2(6.8)$ & $1(3.4)$ & $0(0.0)$ & $3(10.2)$ \\
\hline Bycicle drop & $0(0.0)$ & $0(0.0)$ & $0(0.0)$ & $3(10.3)$ & $3(10.2)$ \\
\hline Sports accident & $0(0.0)$ & $3(10.2)$ & $0(0.0)$ & $0(0.0)$ & $3(10.2)$ \\
\hline Car accident & $0(0.0)$ & $0(0.0)$ & $0(0.0)$ & $1(3.4)$ & $1(3.4)$ \\
\hline
\end{tabular}

\section{Discussion}

The prevalence of TDI found was $4.03 \%$, with no statistically significant difference between genders. Similar results were observed in studies by Campos et al. ${ }^{4}$ and Paiva et al. ${ }^{13}$. Rodrigues et al. ${ }^{9}$ found a prevalence in the deciduous dentition between 
$9.4 \%$ and $62.1 \%$, while in the permanent dentition ranging from $8 \%$ to $58.6 \%$, suggesting that there is a need for a methodological evaluation in the study designs because there are large variations in prevalence.

The dissemination in high-access media of educational campaigns in schools in the city may have contributed to the low prevalence reported in this study, together with the fact that the Unified Health System (SUS) has reorganized its priorities regarding oral health, adopting the model of health promotion with interventions based on risk factors ${ }^{15}$.

The most frequent trauma was enamel and dentin without pulp exposure: $65.5 \%$, followed by enamel crack: $30.6 \%$, in agreement with the findings of Gonçales et al. ${ }^{7}$ and Goettems et al. ${ }^{8}$, but contrary to Jung et $a{ }^{16}{ }^{16}$ who found that the most identified forms of trauma were fractures involving only enamel and fractures involving enamel and dentin. Andersson et al. ${ }^{14,17}$ recommended that the fractured coronary fragment be stored in physiological saline for bonding (because it is a low-cost technique and satisfactory aesthetic results), or restoration with resin if collage was not feasible.

It was observed that the most affected teeth were the permanent upper central incisors. Similar results were observed by Goettems et al. ${ }^{8}$, Reis et al. ${ }^{18}$ and Carvalho et al. ${ }^{19}$, who justified this fact due to eruption before the upper lateral incisors and their position in the dental arch, being subject to a longer period of exposure to risk factors. As for age, it was observed that the age at which most trauma occurred was 11 years with $20.68 \%$, according to studies ${ }^{8-10,13}$. This fact, which can be explained by the greater participation of this age group, in activities, mainly sports that require greater physical effort, with greater risks to dental trauma.

Fall accident was presented as the main cause related to TDI, a correlation also found by Marchiori et al. ${ }^{5}$ and Paiva et al. ${ }^{13}$. The majority of schoolchildren who presented with dental trauma reported that the home and school were the places where the accident occurred, corresponding to $37.9 \%$. Levin et al. ${ }^{20}$ considered the school as the most prone place for the occurrence of trauma. The etiology is correlated to cultural factors and to the types of activities practiced by each community.

From the reported cases of traumatic events, it was observed that of the total number of traumatized teeth found $17 \%$ were treated, with composite resin restorations, with no need to be redone. Of these cases, $0.83 \%$ were in the upper left central incisor, one in the tooth in the upper right lateral incisor and one in the lower right lateral incisor. The low number of previously traumatized teeth that were treated suggests the parents' lack of information about the adequate dental treatment, the difficulty of access to it, and the low socioeconomic status of the population involved in the research. Bonding of coronary fragment in some traumatized tooth was not observed during the examinations.

Although the prevalence of dental trauma is considered low compared to other studies ${ }^{13,18-20}$, it is still a very worrying finding, strategies that guarantee access to health involving preventive and intervention measures, through the dissemination of information on dental trauma and emergency protocols to parents and teachers need to be encouraged. 
It was concluded that the prevalence of dental trauma was $4.03 \%$, with no statistically significant difference between genders. The permanent right upper right central incisor was more affected. The interpretation of the results should be considered as an inherent limitation of the study. It is important that further studies are conducted on the prevalence of dental trauma and its associated etiological factors.

\section{References}

1. Goncalves BM, Dias LF, Pereira CS, Ponte Filho MX, Konrath AC, Bolan MS, et al. The impact of dental traumatism and aesthetical empairment on the quality of life of pre-schools children. Rev Paul Pediatr. 2017;35(4):448-55. doi: 10.1590/1984-0462/;2017;35;4;00011.

2. Traebert J, Claudino D. Epidemiology of dental trauma in children: Brazilian scientific production. Pesq Bras Odontop Clin Integr. 2012 Abr-Jun;12(2):263-72. doi: 10.4034/PBOCI.2012.122.17. Portuguese.

3. Martins VM, Sousa RV, Rocha ES, Leite RB, Gomes MC, Granville-Garcia AF. Assessment of the association between overweight/obesity and traumatic dental injury among brazilian schoolchildren. Acta Odontol. Latinoam. 2014;27(1):26-32.

4. Campos DMKS, Almeida ER, Miotto MHMB, Barcellos LA. Campos FS. Dental trauma: prevalence among adolescents aged 15 to 19 years in the city of Santa Teresa/ES, Brazil. Rev Bras Pesq Saude. 2016 Jul-Sep;18(3):65-73. Portuguese.

5. Marchiori EC, Santos SE, Asprino L, Moraes M, Moreira RW. Occurrence of dental avulsion and associated injuries in patients with facial trauma over a 9-year period. Oral Maxillofac Surg. 2013 Jun;17(2):119-26. doi: 10.1007/s10006-012-0354-5.

6. Pithon MM, Santos RL, Magalhães PHB, Coqueiro RS. Brazilian primary school teachers' knowledge about immediate management of dental trauma. Dental Press J Orthod. 2014 Sept-Oct;19(5):110-5 doi: 10.1590/2176-9451.19.5.110-115.

7. Paiva HN, Paiva PCP, Silva CJP, Lamounier JA, Ferreira EF, Zarzar PM. Use of illicit drugs as a risk factor for dental trauma in adolescents Cad Saude Colet. 2016;24 (3):17-322. doi: 10.1590/1414-462x201600030083. Portuguese.

8. Goettems ML, Torriani DD, Hallal PC, Correa MB, Demarco FF. Dental trauma: prevalence and risk factors in schoolchildren. Community Dent Oral Epidemiol. 2014 Dec;42(6):581-90 doi: 10.1111/cdoe. 12113

9. Rodrigues AS, Castilho T, Antunes LAA, Antunes LS. Epidemiological Profile of Dental Traumatisms in Children and Adolescents in Brazil. UNOPAR Cient Cienc Biol Saude. 2015;17(4):267-78. Portuguese.

10. Soriano EP, Caldas Jr AF, Góes PS. Risk factors related to traumatic dental injuries in Brazilian schoolchildren. Dent Traumatol. 2004 Oct;20(5):246-50. doi: 10.1111/j.1600-9657.2004.00246.x.

11. Peres MA, Traebert J, Marcenes W. Calibration of examiners for dental caries epidemiology studies Cad Saude Publica. 2001 Jan-Feb;17(1):153-9. doi: 10.1590/S0102-311X2001000100016. Portuguese.

12. O'Brien M. Children's dental health in the United Kingdom 1993. In Report of Dental Survey, Office of population Censuses and Survey. London: Her Majesty’s Stationery Office; 1994

13. Paiva PCP, Paiva HN, Filho PMO, Cortês MIS. Prevalence and risk factors associated with traumatic dental injury among 12-year-old schoolchildren in Montes Claros, MG, Brazil. Cienc Saude Colet. 2015 Apr;20(4):1225-33. doi: 10.1590/1413-81232015204.00752014.

14. Andersson L, Andreasen JO, Day P, Heithersay G, Trope M, DiAngelis AJ, et al. International Association of Dental Traumatology guidelines for the management of traumatic dental injuries: 2. Avulsion of permanent teeth. Dent Traumatol. 2012; 28(2):88-96. doi: 10.1111/j.1600-9657.2012.01125.x. 
15. Frujeri MLV, Frujeri JA, Bezerra AC, Cortes MI, Costa ED Jr. Socio-economic indicators and predisposing factors associated with traumatic dental injuries in schoolchildren at Brasília, Brazil: a cross-sectional, population-based study. BMC Oral Health. 2014 July;14(91):1-7. doi:10.1186/1472-6831-14-91.

16. Jung CP, Tsai Al, Chen CM. A 2-year retrospective study of pediatric dental emergency visits at a hospital emergency center in Taiwan. Biomed J. 2016 Jun;39(3):207-13. doi: 10.1016/j.bj.2016.06.004.

17. Andersson L, Andreasen JO, Day P, Heithersay G, Trope M, DiAngelis AJ, et al. International Association of Dental Traumatology guidelines for the management of traumatic dental injuries: 3 . Injuries in the primary dentition. Dent Traumatol. 2012 Jun;28(3):174-82. doi: 10.1111/j.1600-9657.2012.01146.x.

18. Reis AG, Paiva PCP, Oliveira Filho PM. Prevalence of dental trauma and associated factors in 11 to 19-year-old students in the rural areas of the town of Diamantina, MG, Brazil. Arq Cent Estud Curso Odontol Univ Fed Minas Gerais. 2014 Jan/Mar; 50(1):42-8. Portuguese.

19. Carvalho B, Brito AS, Heimer M, Vieira S, Colares V. Dental Injury in Adolescents between 15 and 19 years in Recife- PE, Brazil: Preliminary Study. Pesq Bras Odontoped Clin Integr. 2013;13(1):95-100. doi: 10.4034/PBOCl.2013.131.14. Portuguese.

20. Levin L, Samorodnitzky GR, Schwartz-Arad D, Geiger SB. Dental and oral trauma during childhood and adolescence in Israel: Occurrence, causes, and outcomes. Dent Traumatol. 2007 Dec;23(9):356-9. doi: 10.1111/j.1600-9657.2006.00473.x 